\title{
Impact of Career Planning, Employee Autonomy, and Manager Recognition on Employee Engagement
}

\author{
Franklin M. Lartey \\ Cox Communications, Atlanta, USA \\ Email: franklin@lartey.net
}

How to cite this paper: Lartey, F. M. (2021). Impact of Career Planning, Employee Autonomy, and Manager Recognition on Employee Engagement. Journal of Human Resource and Sustainability Studies, 9, 135-158.

https://doi.org/10.4236/jhrss.2021.92010

Received: March 22, 2021

Accepted: April 22, 2021

Published: April 25, 2021

Copyright ( 2021 by author(s) and Scientific Research Publishing Inc. This work is licensed under the Creative Commons Attribution International License (CC BY 4.0).

http://creativecommons.org/licenses/by/4.0/

(c) (i) Open Access

\begin{abstract}
This study investigated the impact of career planning, employee autonomy, and manager recognition on employee engagement through the lens of the social exchange theory. A survey of 120 employees in US small and medium sized enterprises (SMEs) was conducted and a multiple regression model was created to answer the research questions seeking to know if career planning, employee autonomy, and manager recognition contributed to employee engagement and if so, to what extent. The results supported the theoretical model of social exchange as well as the hypothesized relationships. In other words, data confirmed the existence of a statistically significant relationship between the independent variables: career planning, employee autonomy, and manager recognition, and the dependent variable, employee engagement. Career planning was identified as a better contributor to engagement as compared to the other two predictors. Manager recognition, while contributing less than career planning, was deemed a better contributor compared to employee autonomy. These findings offer implications for research on social exchange theory as an asset for the organization and suggest that in SMEs, managers need to have career planning discussions with their direct reports. These discussions set employees' hopes of a promotion and increase their levels of engagement and involvement. Recognizing employees on a regular basis for a job well-done increases their sense of achievement toward their hoped promotion, thus helping to keep them continuously engaged.
\end{abstract}

\section{Keywords}

Career Planning, Employee Autonomy, Employee Engagement, Manager Recognition, Social Exchange Theory, Work Autonomy 


\section{Introduction}

Identifying the factors that make or keep employees engaged is important in improving their performances and increasing organizational success. For this reason, it is necessary and important to investigate the drivers of engagement in every type of organization and most specifically in small and medium sized enterprises (SMEs). As explained by Bovee, Thill and Mescon (2007), SMEs act as innovators, service providers, suppliers, and distributors to large companies and to the population. Antony, Vinodh, and Gijo (2017) supported this view by affirming that SMEs are a growing sector that contributes to the global economy and represents the backbone of developing countries' economies. SMEs are currently a fundamental part of the US society and economy, as they employ a large number of workers in total that have needs in order to be productive.

Employees are a scarce resource for SMEs because these businesses fully rely on the small pool of workers they employ. As explained by Wynarczyk, Watson, Storey, Short, and Keasey (2016), this situation is different in the case of large enterprises that have larger pools of workers, greater market powers, and enough financial abilities to increase these numbers. With their limited number of employees, SMEs need to increase employee engagement, which would increase productivity, reduce churn, increase profitability, and grow their businesses (Demerouti \& Cropanzano, 2010; Gruman \& Saks, 2011; Macey, Schneider, Barbera, \& Young, 2009).

Many researchers have studied consequences of employee engagement including customer satisfaction (e.g. Coffman, 2000; Salanova, Agut, \& Peiró, 2005); employee performance (e.g. Anitha, 2014; Gull, Khan, \& Sheikh, 2020); employee retention (e.g. Shuck, Twyford, Reio, \& Shuck, 2014); company profitability (e.g. Kazimoto, 2016); and many other consequences such as productivity, safety, organization commitment, etc. Other researchers have studied factors that contribute to employee engagement, including reward and recognition (Saks, 2006); learning opportunities and supervisor support (Sarti, 2014); and work environment (Demerouti, Bakker, Nachreiner, \& Schaufeli, 2001). In their analysis of the determinants of employee engagement, Shantz, Alfes, Truss and Soane (2013) used a sample of 283 participants and measured engagement against five job attributes and task features namely: task significance, task variety, task identity, autonomy, and feedback. They concluded that task variety was the main driver of engagement and found feedback and task significance to be positively associated to engagement. While different studies have focused on the effect of various factors on employee engagement, the current literature does not show any study that focused on the contribution of career planning, employee autonomy, and manager recognition on employee engagement.

The current article seeks to fill the current gap in research by studying the relationship between the independent variables (IV) career planning, employee autonomy, and manager recognition, and the dependent variable (DV) employee engagement. Not only will this fill the current gap in research, but it will 
also have practical implication in the field. To achieve the stated goal, this paper will first present a theoretical perspective and a review of the main constructs of the study before presenting the methodology, results, and discussions.

\section{Literature Review}

\subsection{Employee Engagement}

Employee engagement is a confirmed strategy used to reduce employee churn, increase productivity, stay competitive, and secure organizational growth and survival (Jose \& Mampilly, 2012; Raza et al., 2017). Recent literature suggests that many organizations are updating their strategic plans to include employee engagement. In addition, more and more researchers are seeking to understand antecedents and consequences of employee engagement. In a study of $550 \mathrm{ex}-$ ecutives, the Harvard Business Review (2013) found that 71 percent of respondents identified employee engagement as an important construct to achieve organizational success (Burnett \& Lisk, 2019; Chhetri, 2017; Turner, 2020).

Employee engagement is an emotional commitment of an employee to the organization's mission, vision, values, goals, and purpose. To achieve this commitment, the employee is emotionally and physically present when performing his or her tasks or organizational functions. Kahn (1990) confirmed that employees are engaged when they act emotionally, physically, and cognitively in the performance of their jobs.

In this study, I define employee engagement as a two-way relationship between an organization and a worker in which the organization provides the worker with the environment and conditions to be successful through good leadership and management, and the worker provides the organization with a positive and self-motivated performance leading to the achievement of the organizational mission, vision, purpose, and goals. As defined, engagement suggests the application of the social exchange theory in which each party finds a benefit or reward leading to a continued relationship. One way for an organization to provide conditions to be successful is through goal setting and career planning.

\subsection{Goal Setting}

Goal setting is defined by the Cambridge Dictionary (2020) as "the process of deciding what you want to achieve or what you want someone else to achieve over a particular period." It is the identification and creation of a plan of action to be accomplished by someone or a group of people. Setting goals guides individuals in choosing the appropriate actions to execute in a timely manner. Goal setting has existed in humanity as far back as one can think. For example, any decision to do something in the future can be assimilated to setting a goal.

In recent years, goal setting has attracted various practitioners and researchers. Doran (1981) coined a rule defining proper goal setting technique, suggesting that goals needed to be SMART: Specific, Measurable, Achievable/Attainable, Realistic, and Time-bound. In a subsequent study, Reed, Schifferdecker, and 
Turco (2012) reported that participants who wrote SMARTer goals were more likely to complete their goals as compared to those who wrote SMART goals. This suggests that researchers had added two additional components to the initial SMART goals, namely Evaluative/Ethical and Rewarding, thus the ER in SMARTer. Researchers have also created other goal setting systems such as the $\mathrm{ABC}$ goals (Achievable, Believable, Committed) and the EEE model which stands for Enlighten, Encourage, Enable (Church, Bracken, Fleenor, \& Rose, 2019).

Goal setting by itself does not contribute to performance as much as when combined with feedback. In a nine-month longitudinal study of 209 engineering participants to identify the effects of goal setting and feedback in the work environment, Ivancevich and McMahon (1982) confirmed that feedback was superior to non-feedback, just as goal setting was superior to nongoal-setting. A combination of the two was deemed of greater effect than any single one of them. In the goal setting process, one important aspect for employees is the consideration for career planning. Employees expect that the appropriate accomplishment of their goals year after year would take them to their next career level.

\subsection{Career Planning}

In the current global and competitive business environment, organizations face challenges in retaining high-performing employees. To stay competitive, organizations include career planning in their strategic plans to enhance employees' growth and workforce stability (Donner \& Wheeler, 2001). As explained by Hedge and Rineer (2017), "Careers comprise patterns of work experiences that evolve over time; people typically advance through each successive career stop along this evolutionary path" (p. 1). Careers are not static, and employees need to see the long-term plans of future opportunities offered to them. A survey of 12,000 employees by CEB (2015), a best practice and talent management company now acquired by the technology research and advisory company, Gartner, indicated that career opportunity was the main reason employees joined a different organization as they did not see opportunities to grow in their previous jobs. Career opportunity can be addressed in the workplace through career planning discussions between managers and their employees.

In this study, I view career planning as the process through which a person identifies his or her skills, interests, knowledge, abilities, and aspirations; identifies the jobs or positions that fit with the stated capabilities; and plans the steps and actions providing greater chances of obtaining such positions. The help of a mentor or contributions from the manager are necessary in supporting an employee in the identified career path. Career planning stems from the assumption that once a person starts working in an organization, he or she will be seeking to move up and around the organization functions if given the opportunities, or out if such opportunity does not exist. As explained by Hedge and Rineer (2017), career planning involves the discussion and analysis of the possible career paths of an individual based on his or her strengths, weaknesses, interests, and poten- 
tials. It aids individuals to identify future career options that provide satisfaction as well as challenges that keep them active and interested.

Organizations and their management teams play a key role in fostering their employees' career plans as they need to collaborate with the employees on career development activities, thus enabling them to continuously provide high quality performance in the ever-changing work environment (Arthur, Hall, \& Lawrence, 1989; Donner \& Wheeler, 2001; Hughes et al., 2005; Miller, 1982). A partnership between the manager and the employee is necessary for a proper career planning, and manager recognition helps the employee know that he or she is on the right path toward the completion of steps leading to the next career chapter.

\subsection{Manager Recognition}

In an article published in the Washington Post by Marks (2017), seventeen thousand workers were surveyed in the United States and 71 percent of them said they were actively looking for new jobs, the main reason being the lack of recognition in their current positions. Employee recognition has increasingly gained interest from researchers and organizations. Brun and Dugas (2008) published a qualitative article analyzing employee recognition from the perspective of human resources, seeking to explain the conceptual nuances and limitations of employee recognition. Long and Shield (2010) studied non-cash employee recognition comparing it to cash-based rewards in Canadian and Australian companies and concluded that while popular, non-cash rewards did not substitute cash-based performance programs.

Recognition is the act of offering a reward in relation to a performance such as the accomplishment of a task or project, or the achievement of a goal. It can be monetary in the case of cash awards, or non-monetary in situations of verbal or written praises or appreciations. As explained by Brun and Dugas (2008) and confirmed by Feys, Anseel, and Wille (2013), managers have consistently used recognition programs in the workplace as a motivational instrument. In most cases, manager recognition is in the form of a verbal or written non-monetary appreciation. Many scholars are recommending the increased use of non-monetary incentives by managers in order to enhance employee motivation and drive productivity and satisfaction (Long \& Shields, 2010; Montani, Boudrias, \& Pigeon, 2020).

An article published on Gallup by Mann and Dvorak (2016) explains that "Workplace recognition motivates, provides a sense of accomplishment, and makes employees feel valued for their work. Recognition not only boosts individual employee engagement, but it has also been found to increase productivity and loyalty to the company, leading to higher retention" (p. 1). Manager recognition has indeed been known to increase employees' well-being, willingness to learn, job satisfaction, and intrinsic motivation (Appelbaum \& Kamal, 2000; Merino \& Privado, 2015).

In a study seeking to understand the impact of manager recognition and co- 
worker recognition on employee involvement in the workplace, Montani, Boudrias, and Pigeon (2020) surveyed 249 employees and 151 managers in nine Canadian companies, resulting in 130 usable dyads. Their findings confirmed that manager recognition leads to meaningfulness that contributes to employee behavioral involvement in the workplace. Manager recognition is indeed a motivator for employees, mostly in coordination with a career planning discussion. It has the psychological effect of making the employees feel that they are on track in the accomplishment of their goals, which could potentially unlock their next career objective.

\subsection{Employee Autonomy}

Employees increasingly express a feeling of stress from their workplace due to excessively controlling managers who apply a management style known as micro-management. Chambers (2004) defines micro-management as a behavior exerted by someone who specifies and controls the details of tasks executed by his or her employees, telling them what to do, when, and how. White Jr. (2010) added that this management style prevents subordinates from feeling any type of autonomy, hence the stress created.

In contrast to micromanagement, employee autonomy is a situation known to reduce stress, improve morale, and contribute to well-being (Gagne \& Bhave, 2011). It is presented by Mankins and Garton (2017) as "the single most important element for creating engagement in a company" (p. 1). Employee autonomy is the ability for the employee to decide on the place, the time, and the way to complete their tasks, thus having a say on the when, where, and how. This definition is shared by various researchers such as Bailyn (1993), Chambers (2004), Clark (2001), Gagne and Bhave (2011), and Thompson and Prottas (2005).

The concept of employee autonomy dates back from early management theorists. It is represented in the four principles of Scientific Management as described by Taylor (1911) through the third principle with the notion that "about three-fourths of the time we will work according to whatever method suits us best" (Shafritz \& Hyde, 2012: p. 38). This is an early suggestion of autonomy at work, providing flexibility for employees to make the right work-related decisions.

Employee autonomy has constituted the topic of many research studies. For example, Evans and Fisher (1992) examined workplace practices related to employees' autonomy experience and identified a consistent influence on employee performance. In a study of the relationship among family support, job autonomy, perceived control and employee well-being, Thompson and Prottas (2005) analyzed data from 3504 records in the 2002 National Study of the Changing Workforce in the U.S. Using a hierarchical regression model, their findings showed that job autonomy was associated to all hypothesized outcomes, including job satisfaction, family satisfaction, life satisfaction, stress and well-being, and turnover intentions, among others. As such, while increasing satisfaction 
and well-being, autonomy also improves work-life balance, an enviable situation for workers and organizations.

\section{Theoretical Perspective: Social Exchange Theory}

In 1958, Homans (1958) published an essay titled "Social Behavior as Exchange". This was the inception of the Social Exchange Theory (SET) which was further developed by Gouldner (1960), Homans (1961), Blau (1964), and Emerson (1976). SET is viewed by various researchers as one of the most influential theories for understanding behavior in the workplace (Cropanzano and Mitchell, 2005; Tate, Lartey, and Randall, 2019). Homans (1961) explained that social exchange is the exchange of tangible or intangible items, services, or activities between at least two entities which could include people and groups.

Social Exchange Theory (SET) is a cost-benefit model explaining societal behavior as a set of interactions focused on benefits (rewards) and costs (punishments). In that regard, human interactions are seen as series of actions based on perceived benefits and costs. SET suggests that interactions resulting in approvals (benefits, rewards) are more likely to be repeated than those resulting in disapprovals (punishments, costs). In this view, approvals or benefits are things viewed as positive, resulting from the interaction or the relationship. Disapprovals or costs are things viewed as negative from the interaction. Examples of reward or benefit include financial incentives, social recognition, joy, fun, friendship, acknowledgement, workplace promotion, or success in an exam. Similarly, costs or punishments are things perceived negatively and can also come in many forms including disagreements, reprimands, angriness, wasted time, failure, etc. The social exchange theory model for predicting behavior is provided in formula 1 below:

$$
\begin{aligned}
\text { Interaction }(\text { Behavior })= & \text { Perceived Rewards(Benefits) } \\
& - \text { Perceived Punishments(Costs) }
\end{aligned}
$$

This model suggests that an interaction is likely to be repeated if the perceived rewards or benefits exceed the perceived costs or punishments. In other words, people chose to stay in a relationship with other people or organizations if the perceived benefits of the relationship outweigh the perceived costs.

In applying the principles of SET to the relationship between an employee and an organization, it can be inferred that an employee will stay in an organization and repeat a positive contribution if he or she perceives that there are more benefits than costs in doing so. This was confirmed in a study conducted in Pakistan by Raza, Ansari, Humayon, Hussain, and Aziz (2017) on a sample of 80 government employees. In their study seeking to identify factors affecting millennial employees' engagement, the authors found that the engagement of government teachers was primarily influenced by the government teacher reward and recognition program. This suggests that for teachers, the benefits of the reward and recognition program outweighed the costs of working as a teacher in the government sector. For that reason, teachers stayed with their government employer 
thus reducing churn, and they stayed engaged to be recognized and rewarded, hence increasing overall productivity.

\section{Research Question and Hypotheses}

Several studies have confirmed that employee engagement has a positive effect on performance (Anitha, 2014; Mone and London, 2018; Rich, LePine, and Crawford, 2017). Other studies revealed that personal engagement leads to improved employee performance (Demerouti et al., 2001; Gruman \& Saks, 2011). Career planning discussion, employee autonomy and manager recognition being extrinsic to the employee and engagement being intrinsic, this study hypothesized that career planning discussions with manager, employee autonomy, and manager recognition increase employee engagement which leads to higher performance, thus the following research questions:

RQ1: Does career planning discussions, employee autonomy in accomplishing tasks, and manager recognition contribute to employee engagement?

RQ2: Is there a significant difference in the contribution, if any, of career planning, employee autonomy, and manager recognition in the prediction of employee engagement?

The hypothesis related to these research questions were as follows:

$\mathrm{H}_{0} 1$ : Planning discussions, work autonomy, and manager recognition do not contribute to the increase of employee engagement.

$\mathrm{H}_{\mathrm{A}}$ 1: Planning discussions, work autonomy, and manager recognition contribute to increasing employee engagement.

$\mathrm{H}_{0} 2$ : There is no significant difference in the contribution of career planning, employee autonomy, and manager recognition in the prediction of employee engagement.

$\mathrm{H}_{\mathrm{A}} 2$ : There is a significant difference in the contribution of career planning, employee autonomy, and manager recognition in the prediction of employee engagement.

\section{Conceptual Framework}

In a study seeking to identify drivers of engagement in the workplace, David and Panday (2013) determined that work environment, opportunities to grow, and job enrichment led to employee engagement. Opportunity to grow includes career planning as well as personal development, and work environment encompasses the employees' autonomy to complete assigned tasks.

In a two-month field experiment measuring the effects of goal setting and feedback on productivity in a manufacturing facility, Stansfield and Longenecker (2006) conducted a series of field experiments and confirmed that goal-setting and timely feedback resulted in improved employee performance and higher efficiency. Goal setting was considered by Latham and Locke (1979) as a straightforward technique to drive employee motivation. In this view, manager recognition is a positive feedback provided to the employee for a job well done. 
Additionally, various studies such as those of Anitha (2014), Gull, Khan, and Sheikh (2020), Mone and London (2018), and Rich, LePine, and Crawford (2017) have confirmed the existence of a statistically significant relationship between employee engagement and performance. Based on all the empirical evidence, the current article acknowledges the positive effect of engagement on employee performance and hypothesizes that career planning discussions, employee work autonomy, and manager recognition positively contribute to employee engagement. This theoretical framework is represented on Figure 1.

\section{Methodology}

\subsection{Research Approach}

In analyzing the impact of Career Planning, Employee Autonomy, and Manager Feedback on employee engagement, this study implemented a quantitative non-experimental correlational design approach. It used a self-administered survey questionnaire filled online by randomly selected participants from the online survey firm QuestionPro. The survey questionnaire included two validated instruments to measure the main constructs identified in the conceptual framework.

\subsection{Measurement Instruments}

Employee engagement was measured using the Utrecht Work Engagement Scale (UWES-9) created by Schaufeli, Bakker, and Salanova (2006). This instrument has been validated across studies in different countries as explained by Tate, Lartey, and Randall (2019) and is considered one of the most used employee engagement instruments (Mone \& London, 2018). UWES-9 is a 9-item scale measuring employee engagement organized in three dimensions or subscales, namely vigor, dedication, and absorption. These dimensions are measured from their subtending variables (attitudes or behaviors) using a 5-point Likert scale ranging from never coded as 1 , to always, coded 5 , with the mid-point 3 worded as sometimes.

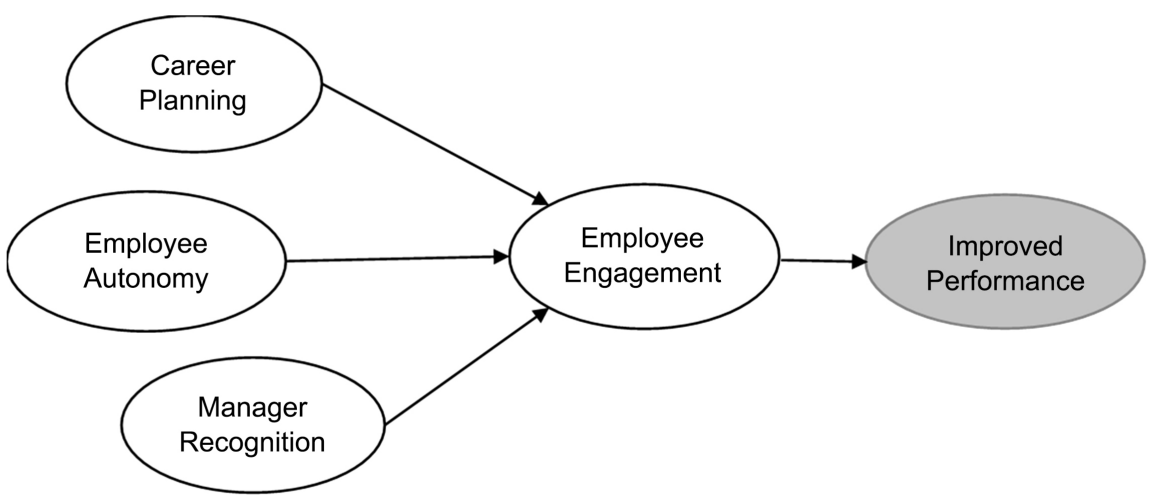

Figure 1. Theoretical Framework of the study suggesting that career planning discussions, employee work autonomy, and manager recognition contribute to employee engagement which leads to increased performance. 
Career planning, employee autonomy, and manager recognition were measured using their related items from the Path Model Indirect Predictors of the performance and engagement model developed by Mone and London (2018). These items rate the assertions: "I had a career-planning discussion with my manager" for career planning discussion, "I have control over the quality of my work" for employee autonomy, and "I am satisfied with the recognition I receive from my manager" for manager recognition.

\subsection{Population and Sample Size}

In conducting this study, data were collected using an online survey questionnaire targeting employees in small and medium-sized businesses in the United States of America (U.S.). A total of 120 candidates validly filled the questionnaires. This number was initially selected through an a-priori power analysis providing the sample size needed to achieve appropriate power given the error probability $(\alpha=0.05)$, the expected power $(1-\beta$ error probability $=0.95)$, the number of tested predictors $(\mathrm{m}=3)$, and the total number of predictors collected of 19. The total number of predictors collected was informed by the path model indirect predictors of employee engagement related to performance management as presented by Mone and London (2018), which includes 19 different items. The result of the a-priori power calculation suggested a required sample size of 120 , providing an actual power of 0.95 , which is well above the minimum suggested power of 0.8 as confirmed by Field (2013). As a result, the sample size for this study was made of 120 participants, all employees of small and medium size enterprises in the U.S. As noted, this sample size was adequate for such study as supported by literature. For example, Saks (2006) used a sample of 102 to determine the antecedents and consequences of employee engagement using multiple regression. Similarly, in their study seeking to identify drivers of engagement in the workplace, David and Panday (2013) used a sample of 107 participants in the pharmaceutical and IT industry.

\section{Data Analysis}

The data analysis proceeded first with a post-hoc power analysis to confirm if the expected power was obtained with the final sample. That was followed by an analysis of the reliability of the survey questionnaire using the Cronbach Alpha test (Cronbach, 1951), and the analysis of the assumptions of multiple regression. Finally, a standard multiple regression model was created to test the hypothesis, and the interpretation of the results concluded the data analysis section.

\subsection{Post-Hoc Power Analysis}

A post-hoc analysis was conducted to validate the adequacy of the sample size used in this study by calculating the achieved power based on the study's sample. Power analysis was computed using the statistical power analysis package GPower 3.1.7 suggested by Faul, Erdfelder, Lang, and Buchner (2007). The base- 
line of the power calculation included the error probability $(\alpha=0.05)$, the sample size $(s=120)$, the effect size $\left(f^{2}=0.15\right)$, and the number of independent variables or predictors (three). The effect size was selected based on Cohen's (1977) recommendation suggesting three possible effect sizes namely small $\left(f^{2}=0.02\right)$, medium $\left(f^{2}=0.15\right)$, and large $\left(f^{2}=0.35\right)$. Additional selections were made to fine-tune the results of the power analysis, including the test family (F tests); the statistical test (Linear multiple regression: Fixed model, $\mathrm{R}^{2}$ increase); and the type of analysis (Post hoc: Compute achieved power-give $\alpha$, sample size, and effect size).

The results of the post-hoc analysis showed a statistical power of 0.95 for detecting medium effect sizes. These results were identical when changing the statistical test to "Linear multiple regression: Fixed model, $\mathrm{R}^{2}$ deviation from zero." As such, the achieved power of 0.95 confirmed that the sample size was adequate for answering the research question. This conclusion is supported by Cohen (1992) who suggests that adequate power for answering research questions is achieved for values greater than 0.80 . As a result, the achieved power of 0.95 was deemed appropriate to proceed with the data analysis using the current sample size of 120 participants but prior to data analysis, the reliability and validity of the survey instrument needed to be established.

\subsection{Reliability and Validity of the Survey Instrument}

As explained in paragraph 6.2., the validity of the instrument used in this study has been confirmed in prior studies. The reliability of the survey instrument was assessed using the Cronbach Alpha statistic. The Cronbach alpha test was computed against the collected data to analyze the internal consistency and reliability of the survey instrument. That was achieved with SPSS using the function Analyze/Scale/Reliability Analysis. Twelve items were added to the items list namely the nine items of the UWES-9 scale and the three behavior variables representing the independent variables (CAREERPLAN, AUTONOMY, and RECOGNITION). The results of the Cronbach alpha calculation on 120 records and 12 variables ( 9 constituting the outcome and 3 for the predictors) showed an alpha coefficient of 0.94 . The rule of thumb implemented by most researchers is to have a minimum coefficient of 0.70 to consider the level of internal self-consistency of an instrument suitable for the study (Taber, 2018). As such, the coefficient alpha of 0.94 suggested a high internal consistency and reliability of the survey instrument, thus allowing the study to proceed with the data analysis without any need for variable reduction.

\subsection{Assumption of Multiple Regression}

To analyze the impact of career planning, manager feedback, and autonomy on employee engagement, this study used three independent variables (CAREERPLAN, AUTONOMY, and RECOGNITION) and one dependent variable (ENGAGEMENT). While the independent variables were individual behaviors or attitudinal variables, engagement was a latent variable corresponding to the sum of 
its nine underlying behavior variables as represented in the UWES-9 instrument. All variables were of scale measurement level and suitable for the creation of a multiple regression model. Prior to the model creation, the assumptions of multiple regression needed to be confirmed. As presented by Lartey (2020), these assumptions include: 1) the ratio of cases to independent variables; 2) the absence of outliers among the independent and the dependent variables (univariate and multivariate outliers); 3) normality, linearity, and homoscedasticity; 4) the absence of multicollinearity and singularity; and 5) the independence of errors in the solution.

\subsubsection{Ratio of Cases to Independent Variables}

According to Tabachnick and Fidell (2013), the minimum number of cases required is $\mathrm{n} \geq 50+8 \mathrm{~m}$ for testing multiple correlation, or $\mathrm{n} \geq 104+\mathrm{m}$ for testing individual variables, assuming $\alpha=0.05$ and $\beta=0.20$, suggesting a medium-size relation between independent variables and dependent variables. In these formulae, $\mathrm{n}$ is the total number of cases and $\mathrm{m}$ is the number of independent variables. Other researchers suggest less stringent recommendations. For example, Khamis and Kepler (2010) suggest using $\mathrm{n} \geq 20+5 \mathrm{~m}$ when dealing with validations. Based on these three recommendations and considering the information for this study where $\mathrm{m}=3$, the minimum suggested number of participants is respectively $n \geq 74(50+8 \times 3) ; n \geq 107(104+3)$; and $n \geq 35(20+5 \times 3)$. With 120 participants and 3 independent variables, this study meets the minimum requirements and the assumption of cases to independent variables was met.

\subsubsection{Univariate Outliers and Missing Values}

There were no missing values in the 120 responses retained for this study. To identify possible univariate outliers, the z-scores of all variables were computed on SPSS using the function Analyze/Descriptive Statistics/Descriptives and selecting Save standardized values as variables. A subsequent descriptive statistic of the newly created variables was done selecting only the minimum and maximum dispersions from the options. The resulting information presented on $\mathrm{Ta}$ ble 1 showed that none of the $\mathrm{z}$-scores was outside the range from -3.29 to +3.29 as suggested by Tabachnick and Fidell (2013). As such, in addition to not having any missing information, the data did not include any univariate outlier.

Table 1. Z-scores of the independent and dependent variables. None was out of the range -3.29 to 3.29 confirming the absence of univariate outliers.

\begin{tabular}{cccc}
\hline & $\mathrm{N}$ & Minimum & Maximum \\
\hline Zscore (ENGAGEMENT) & 120 & -2.57359 & 1.65697 \\
Zscore (CAREERPLAN) & 120 & -1.53472 & 1.68216 \\
Zscore (AUTONOMY) & 120 & -3.07407 & 0.97965 \\
Zscore (RECOGNITION) & 120 & -1.93641 & 1.29094 \\
Valid N (listwise) & 120 & & \\
\hline
\end{tabular}




\subsubsection{Multivariate Outliers}

To identify the presence of multivariate outliers, the Mahalanobis distance was computed for all records using the SPSS function Analyze/Regression/Linear and selecting Mahalanobis in the Distances box from the Save option. This created a new variable named MAH_1 in the dataset. Next, the probability that a value from the chi-square distribution with 3 degrees of freedom would be lower than the related Mahalanobis distance was computed using the Equation (1)—CDF.CHISQ (MAH_1, 3). This equation is the same as using SIG.CHISQ (MAH_1, 3). In both equations, 3 represents the degrees of freedom or number of independent variables in this study. Any resulting variable with a value below the desired alpha of 0.05 would represent a multivariate outlier.

A new variable named PROBABILITY_MAH_1 was created using the SPSS function Transform/Compute Variable, the target variable PROBABILITY_ MAH_1, and the numeric expression 1-CDF.CHISQ (MAH_1, 3). Looking at the descriptive statistic of the created variable, 10 cases had a probability value below 0.05 suggesting multivariate outliers and were removed from the dataset through the creation of a new variable named SELECT. This variable was created using Transform/Compute Variable and entering the variable SELECT as target variable and the value 1 as numeric expression. In the data view, after sorting the data on PROBABILITY_MAH_1, the value of SELECT was changed to zero for those first 10 records and the cases were removed from the selection by using the function Data/Select Cases/Use filter variable and selecting SELECT. This ensured that any record with SELECT value of 0 would be removed from the statistics.

A new Mahalanobis distance MAH_2 was computed for the selected 110 cases, followed by the related probability PROBABILITY_MAH_2. Of the remaining 110 cases, one had a probability value of 0.04 , shy of the required 0.05 but was kept in the dataset because its influence on the other 109 cases was deemed negligible. The new dataset with 110 records was still deemed usable for multiple regression as it satisfied all the assumptions previously presented.

\subsubsection{Normality, Linearity, and Homoscedasticity}

The assumption of normality, linearity, and homoscedasticity was conducted through the analysis of residuals. This is supported by Tabachnick and Fidell (2013) who explain that "Routine pre-analysis screening procedures of Chapter 4 may be used to assess normality, linearity, and homoscedasticity. Regression programs, however, also offer an assessment of the three assumptions simultaneously through analysis of residuals produced by the programs" (p. 125). To that effect, a scatterplot was created using the SPSS function Analyze/Regression/ Linear. The standardized predicted values (ZPRED) were placed on the x-axis and the standardized residuals (ZRESID) were placed on the $y$-axis. The resulting plot showed a non-curved and almost rectangular pattern, with no residual value outside the range from -3 to +3 . Also, there was an almost equal number of residuals above the zero line of the plot as below, meaning that residuals had a horizontal line relationship with the predicted values, and the variance of the re- 
siduals were not too far for all predicted scores. In other words, the band enclosing the residuals stayed almost equal in width for all values of the predicted dependent values and did not become wider at larger predicted values. All this suggested that the assumptions of normality, linearity, and homoscedasticity were met.

In addition, the P-P plot of the standardized residuals and the regression standardized residual histogram showed a normal distribution confirming that standardized residuals were normally distributed. Notwithstanding this, the assumption of normality was also confirmed by analyzing the skewness and kurtosis of all variables. Using the SPSS functions Analyze/Descriptive Statistics/Descriptives and selecting Kurtosis and Skewness in the options, the resulting output on Table 2 shows the related skewness and kurtosis values. All values of skewness and kurtosis are between -1 and +1 , suggesting that all variables are reasonably normally distributed.

\subsubsection{Independence of Errors}

The Durbin-Watson test statistic for detecting the presence of autocorrelation in the residuals had a value of 2.02. As a reference, values of the Durbin-Watson test are always between 0 and 4 . Values less than 2 suggest positive autocorrelation while those greater than 2 suggest negative correlation. A value of 2 means there is no autocorrelation. As explained by Field (2013), values below 1 or above 3 are causes for concern. The Durbin-Watson test statistic of 2.02 confirms that there was no serial correlation of the residuals from one observation to another, confirming the assumption of independence of error.

\subsubsection{Multicollinearity and Singularity}

Collinearity diagnostics were analyzed through the variance inflation factor (VIF) and the tolerance. Each IV or DV served in turn as DV while the other variables served as IV and the VIF and tolerance were computed as suggested by Tabachnick and Fidell (2013) and Field (2013). The results are summarized on Table 3 for the VIFs and on Table 4 for the tolerances. A review of Table 3 shows that all VIF values are well below the critical limit of 10 considered risky for collinearity. Similarly, Table 4 confirms that the tolerance statistics computed as 1 - SMC (squared multiple correlation) are all above 0.2 as suggested by Field. Finally,

Table 2. Descriptive statistics of the independent and dependent variables showing all skewness and kurtosis within -1 to 1 range, suggesting a reasonable normal distribution because values are nearer to zero.

\begin{tabular}{ccccccccc}
\hline & N Statistic & Minimum & Maximum & \multicolumn{2}{c}{ Skewness } & \multicolumn{2}{c}{ Kurtosis } \\
\cline { 6 - 8 } & & & & Statistic & Std. Error & Statistic & Std. Error \\
\hline ENGAGEMENT & 110 & 12 & 54 & -0.246 & 0.230 & -0.798 & 0.457 \\
CAREERPLAN & 110 & 1 & 5 & 0.070 & 0.230 & -0.803 & 0.457 \\
RECOGNITION & 110 & 1 & 5 & -0.609 & 0.230 & -0.337 & 0.457 \\
AUTONOMY & 110 & 2 & 5 & -0.658 & 0.230 & 0.021 & 0.457 \\
Valid N (listwise) & 110 & & & & & & \\
\hline
\end{tabular}


Table 3. Summary of the VIFs with each variable serving in turn as dependent variable. There is no value above 10 , suggesting the absence of multicollinearity.

\begin{tabular}{ccccc}
\hline \multirow{2}{*}{$\begin{array}{c}\text { Dependent } \\
\text { Variables }\end{array}$} & \multicolumn{4}{c}{ Independent Variables } \\
\cline { 2 - 5 } & ENGAGEMENT & CAREERPLAN & AUTONOMY & RECOGNITION \\
\hline ENGAGEMENT & - & 1.454 & 1.306 & 1.736 \\
CAREERPLAN & 1.653 & - & 1.364 & 1.744 \\
AUTONOMY & 2.053 & 1.886 & - & 1.704 \\
RECOGNITION & 1.981 & 1.750 & 1.237 & - \\
\hline
\end{tabular}

Table 4. Summary of the tolerances with each variable serving in turn as dependent variable. There is no value below 0.20 , confirming the absence of multicollinearity.

\begin{tabular}{ccccc}
\hline \multirow{2}{*}{$\begin{array}{c}\text { Independent } \\
\text { Variables }\end{array}$} & \multicolumn{4}{c}{ Dependent Variables } \\
\cline { 2 - 5 } & ENGAGEMENT & CAREERPLAN & AUTONOMY & RECOGNITION \\
\hline ENGAGEMENT & - & 0.688 & 0.766 & 0.576 \\
CAREERPLAN & 0.605 & - & 0.733 & 0.573 \\
AUTONOMY & 0.487 & 0.530 & - & 0.587 \\
RECOGNITION & 0.505 & 0.571 & 0.809 & - \\
\hline
\end{tabular}

analyzing collinearity using the SPSS function Analyze/Correlate/Bivariate revealed no correlation value among IVs above 0.6 , with 0.7 being the limit of concern (Field, 2013). Based on what precedes, multicollinearity and singularity did not create any cause for concern and the assumption suggesting the absence of multicollinearity and singularity was achieved.

\section{Results}

The results of the evaluation of assumptions of multiple regression led to the suppression of ten cases identified as multivariate outliers based on their Mahalanobis distances with the use of the criterion $p<0.05$. As such, the sample size for the analysis went from 120 to $\mathrm{N}=110$ cases. The ratio of cases to independent variables confirmed the adequacy of the sample of $\mathrm{N}=110$. A subsequent post-hoc analysis was conducted to validate the adequacy of the final sample size used in this study, based on the same parameters as the previous post hoc analysis. The results confirmed the adequacy of the sample with an achieved power of .93, as compared to 0.95 for the sample size of 120 participants. There were no missing cases or univariate outliers in the dataset. All other assumptions were validated including normality, linearity, and homoscedasticity; absence of multicollinearity and singularity; and independence of errors in the solution.

A standard multiple regression model was created to assess the impact of career planning (CAREERPLAN), employee autonomy (AUTONOMY), and manager recognition (RECOGNITION) on employee engagement (ENGAGEMENT). To 
achieve this, the SPSS function Analyze/Regression/Linear was used with the dependent variable ENGAGEMENT and the independent variables CAREERPLAN, AUTONOMY, and RECOGNITION. The resulting model suggested that a significant regression equation was found $F(3,106)=40.90, p<0.001$ as shown on Table 5, with $R^{2}=0.53$ as shown on the model summary on Table 6 . The analysis of variance (ANOVA) tests if the R-Square is significantly greater than 0 . The $p$-value shown on Table 5 being less than 0.001 suggests that the $R$-Square of the solution is significantly greater than zero. As such, the predictors can account for an acceptable amount of variance in the employee engagement score.

Table 7 displays the details of the final model with the unstandardized regression coefficients (B), the standardized coefficients (Beta), the p-value or significance of each independent variable (sig), the intervals for B at $95 \%$ percentage confidence, and the collinearity statistics. Based on these details on the model $F$ $(3,106)=40.90, p<0.001, R^{2}=0.53$, and the fact that the $p$-values of all three independent variables were significant $(p<0.05)$, the null hypothesis $\mathrm{H}_{0} 1$ was rejected and the alternate hypothesis $\mathrm{H}_{\mathrm{A}} 1$ retained. As such, there was enough evidence suggesting that career planning discussion (CAREERPLAN), employee autonomy (AUTONOMY), and manager recognition (RECOGNITION) contributed to determining employee engagement (ENGAGEMENT) among workers of small and medium sized businesses. Looking at the model summary presented on Table 6, the $R$-square of 0.537 indicates that 53.7 percent of variance in employee engagement scores related to the sample was accounted for by the independent variables CAREERPLAN, AUTONOMY, and RECOGNITION. The adjusted $R^{2}$ value of 0.523 indicates that 52.3 percent of variability in employee engagement among the population of workers of small and medium sized businesses can be explained using the three observed variables CAREERPLAN, AUTONOMY, and RECOGNITION.

Table 5. Analysis of variance (ANOVA ${ }^{\mathrm{a}}$ ) showing a significant $F$ statistic confirming that the $R$-Square of the solution is significantly greater than zero.

\begin{tabular}{ccccccc}
\hline \multicolumn{1}{c}{ Model } & Sum of Squares & df & Mean Square & F & Sig. \\
\hline & Regression & 6272.081 & 3 & 2090.694 & 40.906 & $0.000^{\mathrm{b}}$ \\
1 & Residual & 5417.637 & 106 & 51.110 & & \\
& Total & 11689.718 & 109 & & & \\
\hline
\end{tabular}

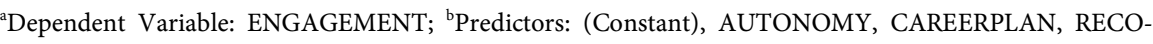
GNITION.

Table 6. Model summary showing an $R^{2}$ of 0.537 .

\begin{tabular}{cccccc}
\hline Model & $\mathrm{R}$ & R Square & $\begin{array}{c}\text { Adjusted R } \\
\text { Square }\end{array}$ & $\begin{array}{c}\text { Std. Error of } \\
\text { the Estimate }\end{array}$ & Durbin-Watson \\
\hline 1 & $0.732^{\mathrm{a}}$ & 0.537 & 0.523 & 7.149 & 2.026 \\
\hline
\end{tabular}

aPredictors: (Constant), AUTONOMY, CAREERPLAN, RECOGNITION. 
Table 7. Model summary showing an $R^{2}$ along with all predictors, their unstandardized and standardized coefficients ${ }^{\mathrm{a}}$, their significances, and other statistics. All three predictors are statistically significant in predicting the outcome variable (employee engagement).

\begin{tabular}{|c|c|c|c|c|c|c|c|c|c|c|}
\hline & \multirow{2}{*}{ Model } & \multicolumn{2}{|c|}{$\begin{array}{l}\text { Unstandardized } \\
\text { coefficients }\end{array}$} & \multirow{2}{*}{$\begin{array}{c}\text { Stdzcoef. } \\
\text { Beta }\end{array}$} & \multirow{2}{*}{$\mathrm{t}$} & \multirow{2}{*}{ Sig. } & \multicolumn{2}{|c|}{$\begin{array}{l}95.0 \% \text { Confidence } \\
\text { Interval for B }\end{array}$} & \multicolumn{2}{|c|}{ Collinearity Statistics } \\
\hline & & B & Std. Error & & & & $\begin{array}{l}\text { Lower } \\
\text { Bound }\end{array}$ & $\begin{array}{l}\text { Upper } \\
\text { Bound }\end{array}$ & Tolerance & VIF \\
\hline \multirow{4}{*}{1} & (Constant) & 6.843 & 3.683 & & 1.85 & 0.066 & -0.460 & 14.145 & & \\
\hline & CAREERPLAN & 4.035 & 0.709 & 0.454 & 5.69 & 0.000 & 2.630 & 5.441 & 0.688 & 1.45 \\
\hline & AUTONOMY & 2.279 & 0.980 & 0.176 & 2.32 & 0.022 & 0.335 & 4.222 & 0.766 & 1.30 \\
\hline & RECOGNITION & 2.423 & 0.787 & 0.268 & 3.07 & 0.003 & 0.862 & 3.984 & 0.576 & 1.73 \\
\hline
\end{tabular}

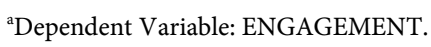

The standardized coefficients Beta as shown on Table 7 indicate the contribution of each independent (IV) variable in the determination of the dependent variable. To that effect, Table 7 shows that of all IV, the most significant predictor of engagement is career planning (Beta $=0.45$ ). This is followed by RECOGNITION (Beta $=0.27$ ), then AUTONOMY (Beta $=0.17$ ). These findings helped answer the second research question: "Is there a significant difference in the contribution, if any, of career planning, employee autonomy, and manager recognition in the prediction of employee engagement". The null hypothesis $\mathrm{H}_{0} 2$ of non-existence of a difference among independent variables was rejected and the alternate hypothesis $\mathrm{H}_{\mathrm{A}} 2$ was retained. Hence, this study confirmed that there was a significant difference in the contribution of career planning, employee autonomy, and manager recognition in the prediction of employee engagement, with career planning being the top contributor of engagement.

\section{Discussions and Practical Implications}

The purpose of this social exchange-based study was to investigate the impact of career planning, employee autonomy, and manager recognition on employee engagement, which leads to performance increase and contributes to the achievement of organizational goals. To that effect, 120 employees in small and medium enterprises in the United States were randomly selected for an online survey. Of the 120 participants, 110 were retained for the creation of the final model after the elimination of 10 cases identified as multivariate outliers. The results of the study supported the social exchange theoretical model and the hypothesized relationships. In other words, it was determined that career planning, employee autonomy, and manager feedback contributed positively to employees' engagement, accounting for over 53 percent of variability in the engagement construct. The social exchange theory suggests that individuals perform better when motivated by an expected return (Tate, Lartey, \& Randall, 2019). In alignment with that view, this study identified the expected return as possible career promotion opportunities anchored on the career planning discussions. The feel- 
ing of achievement of this expected reward is enforced by the employee's autonomy. In other words, the employee feels trusted to make decisions and choices in the accomplishment of his or her tasks. The "carrot" or anticipation of a reward is the confirmation of being on the right path, a recognition by the employee's manager. As presented, this study served as a platform to investigate and validate some conditions that can motivate employees and keep them engaged as they feel confident about a possible reward.

The findings of this study have meaningful and important implications for organizations and their leadership. One implication suggests that organizations can create a simple 3-step plan for keeping their employees engaged. First, the employees need to know that they have an opportunity to progress within the company. Such progression could be within the employee's current job, toward supervisory and management roles, or moving to a completely different department or branch of the organization. To address this, it is a good practice to create progression plans for every existing position. In addition to the perception of future progression, employees need to be trusted in their current role. Such trust could manifest itself by the sense of autonomy provided by supervisors to employees in the accomplishment of their tasks. In other words, supervisors should avoid micro-managing their employees as much as possible. Finally, recognizing employees is a way of confirming that they are on the right path toward achieving the expected promotion or recommendation for a future position. Together, these three elements create intrinsic and extrinsic forces that motivate employees, thus enhancing their engagement and performance.

From an academia standpoint, this work contributed to knowledge in the field of study by filling a gap in existing literature. Indeed, no previous study looking at the contribution of the three items, career planning, employee autonomy, and manager recognition, to employee engagement was found in the literature. Hence, the current study provided empirical evidence confirming such relationship. In addition, the definition of engagement as presented here is different from those previously provided by some researchers. As explained earlier, this study defined engagement not just in relation to the employee, but also including the organization in which the employee works. It defined engagement as "a two-way relationship between an organization and a worker, in which the organization provides the worker with the environment and conditions to be successful through good leadership and management, and the worker provides the organization with a positive and self-motivated performance leading to the achievement of the organizational mission, vision, purpose, and goals." Despite the noteworthy findings and contributions provided by this study, there were limitations worth discussing.

\section{Limitations and Future Prospects}

Notwithstanding the fact that this study made significant contributions to both research and practice, it still has some limitations worth presenting. First, the study used self-administered online questionnaires allowing the participants to 
provide answers without explaining the reasons for their choices. In such setting, there could be data bias as some participants could systematically fill their questionnaires without utterly understanding the question. While some controls were implemented to prevent such situation, some data could have passed through and made it into the analysis.

Another shortfall of the study is the limitation of the sample to small and medium sized enterprises in the United States. For that reason, the findings of the study should not be generalized to large enterprises or to other countries. Further research is required prior to such generalization and this would constitute a possible topic for future studies.

\section{Conclusion}

The premise of this research was to study the impact of career planning, employee autonomy, and manager reward on employee engagement. The research was grounded on employee engagement from the perspective of the social exchange theory. The first research question asked if career planning discussions, employee autonomy in accomplishing tasks, and manager recognition contributed to employee engagement. The second research question asked if there was a significant difference in the contribution, if any, of career planning, employee autonomy, and manager recognition in the prediction of employee engagement.

A standard multiple regression model was created to answer the research questions. Results of the analysis confirmed the existence of a statistically significant relationship between the independent variables in determining employee engagement among workers in small and medium sized enterprises. The findings also confirmed the existence of differences in the predictors' contributions. To that effect, career planning was identified as the best contributor to employee engagement as compared to employee autonomy and manager recognition. The latter, manager recognition, had a higher contribution to engagement compared to employee autonomy.

This study contributed to academia by filling the gap in the existing literature related to predictors of engagement. It provided empirical evidence of the extent to which career planning discussions have the propensity of influencing employee engagement. It also showed that career planning discussions, employee autonomy, and manager recognition explained as much as 53 percent of employee engagement. These findings also have considerable implications for practitioners and organizations, suggesting that organizations should encourage and mandate career planning discussions between supervisors and their direct reports. Providing a vision of the possible future is like giving hope to employees, which allows them to increase their engagement and performance in the pursuit of their dreams of moving to the next career level.

\section{Conflicts of Interest}

The author declares no conflicts of interest regarding the publication of this paper. 


\section{References}

Anitha, J. (2014). Determinants of Employee Engagement and Their Impact on Employee Performance. International Journal of Productivity and Performance Management, 63, 308-323. https://doi.org/10.1108/IJPPM-01-2013-0008

Antony, J., Vinodh, S., \& Gijo, E. V. (2017). Lean Six Sigma for Small and Medium Sized Enterprises: A Practical Guide. UK: CRC Press. https://doi.org/10.1201/9781315372174

Appelbaum, S. H., \& Kamal, R. (2000). An Analysis of the Utilization and Effectiveness of Nonfinancial Incentives in Small Business. Journal of Management Development, 19, 733-763. https://doi.org/10.1108/02621710010378200

Arthur, M. B., Hall, D. T., \& Lawrence, B. S. (1989). Handbook of Career Theory. Cambridge: Cambridge University Press. https://doi.org/10.1017/CBO9780511625459

Bailyn, L. (1993). Breaking the Mold: Women, Men, and Time in the New Corporate World. New York: Free Press.

Blau, P. M. (1964). Exchange and Power in Social Life. New York: John Wiley.

Bovee, C., Thill, J., \& Mescon, M. (2007). Excellence in Business (3rd ed.). New York, NY: Pearson Prentice Hall.

Brun, J. P., \& Dugas, N. (2008). An Analysis of Employee Recognition: Perspectives on Human Resources Practices. The International Journal of Human Resource Management, 19, 716-730. https://doi.org/10.1080/09585190801953723

Burnett, J. R., \& Lisk, T. C. (2019). The Future of Employee Engagement: Real-Time Monitoring and Digital Tools for Engaging a Workforce. International Studies of Management \& Organization, 49, 108-119.

https://doi.org/10.1080/00208825.2019.1565097

Cambridge Dictionary (2020). Goal Setting. Cambridge Dictionary Online. https://dictionary.cambridge.org/us/dictionary/english/goal-setting

CEB (2015). Seventy Percent of Employees Unhappy with Career Opportunities. https://www.prnewswire.com/news-releases/seventy-percent-of-employees-unhappy-w ith-career-opportunities-300178571.html

Chambers, H. E. (2004). My Way or the Highway: The Micromanagement Survival Guide. San Francisco, CA: Berrett-Koehler Publishers.

Chhetri, S. B. (2017). Antecedents and Consequences of Job Engagement: Empirical Study of Bank Employees. Business Perspectives and Research, 5, 167-179. https://doi.org/10.1177/2278533717692919

Church, A. H., Bracken, D. W., Fleenor, J. W., \& Rose, D. S. (2019). Handbook of Strategic 360 Feedback. New York: Oxford University Press. https://doi.org/10.1093/oso/9780190879860.001.0001

Clark, S. C. (2001). Work Cultures and Work/Family Balance. Journal of Vocational Behavior, 58, 348-365. https://doi.org/10.1006/jvbe.2000.1759

Coffman, C. (2000). Is Your Company Bleeding Talent? How to Become a True "Employer of Choice”. Princeton, NJ: Gallup Organization.

Cohen, J. (1977). Statistical Power Analysis for the Behavioral Sciences (Rev. ed.). Hillsdale, NJ: Lawrence Erlbaum Associates, Inc.

Cohen, J. (1992). A Power Primer. Psychological Bulletin, 112, 155-159. https://doi.org/10.1037/0033-2909.112.1.155

Cronbach, L. J. (1951). Coefficient Alpha and the Internal Structure of Tests. Psychometrika, 16, 297-334. https://doi.org/10.1007/BF02310555

Cropanzano, R., \& Mitchell, M. S. (2005). Social Exchange Theory: An Interdisciplinary 
Review. Journal of Management, 31, 874-900. https://doi.org/10.1177/0149206305279602

David, S., \& Panday, S. (2013). A Study of Engagement at Work: What Drives Employee Engagement? European Journal of Commerce and Management Research, 2, 155-161.

Demerouti, E., \& Cropanzano, R. (2010). From Thought to Action: Employee Work Engagement and Job Performance. In A. B. Bakker, \& M. P. Leiter (Eds.), Work Engagement: A Handbook of Essential Theory and Research (pp. 147-163). Hove, East Sussex: Psychology Press.

Demerouti, E., Bakker, A. B., Nachreiner, F., \& Schaufeli, W. B. (2001). The Job Demands-Resources Model of Burnout. Journal of Applied Psychology, 86, 499-512. https://doi.org/10.1037/0021-9010.86.3.499

Donner, G. J., \& Wheeler, M. M. (2001). Career Planning and Development for Nurses. International Nursing Review, 48, 79-85. https://doi.org/10.1046/j.1466-7657.2001.00028.x

Doran, G. T. (1981). There's a S.M.A.R.T. Way to Write Managements' Goals and Objectives. Management Review, 70, 35-36.

Emerson, R. M. (1976). Social Exchange Theory. Annual Review of Sociology, 2, 335-362. https://doi.org/10.1146/annurev.so.02.080176.002003

Evans, B. K., \& Fischer, D. G. (1992). A Hierarchical Model of Participatory Decision-Making, Job Autonomy, and Perceived Control. Human Relations, 45, 1169-1189. https://doi.org/10.1177/001872679204501103

Faul, F., Erdfelder, E., Lang, A.-G., \& Buchner, A. (2007). GPower 3: A Flexible Statistical Power Analysis Program for the Social, Behavioral, and Biomedical Sciences. Beharior Research Methods, 39, 175-191. https://doi.org/10.3758/BF03193146

Feys, M., Anseel, F., \& Wille, B. (2013). Responses to Co-Workers Receiving Recognition at Work. Journal of Managerial Psychology, 28, 492-510. https://doi.org/10.1108/JMP-08-2011-0025

Field, A. (2013). Discovering Statistics Using IBM SPSS Statistics (4th ed.). Thousand Oaks, CA: SAGE Publications.

Gagne, M., \& Bhave, D. P. (2011). Autonomy in the Workplace: An Essential Ingredient to Employee Engagement and Well-being in Every Culture. In Human Autonomy in Cross-Cultural Context: Perspectives on the Psychology of Agency, Freedom, and Well-Being (Vol. 1, pp. 163-187). Research Collection Lee Kong Chian School of Business. https://doi.org/10.1007/978-90-481-9667-8_8

Gouldner, A. W. (1960). The Norm of Reciprocity: A Preliminary Statement. American Sociological Review, 25, 161-178. https://doi.org/10.2307/2092623

Gruman, J. A., \& Saks, A. M. (2011). Performance Management and Employee Engagement. Human Resource Management Review, 21, 123-136.

https://doi.org/10.1016/j.hrmr.2010.09.004

Gull, I. A., Khan, A., \& Sheikh, A. M. (2020). Employee Engagement-Performance Relationship through Innovative Work Behaviour and Intention to Stay. International Journal of Information, Business and Management, 12, 79-87.

Harvard Business Review (2013). The Impact of Employee Engagement on Performance. Harvard Business Review Analytic Services Report.

https://talentsnapshot.com/wp-content/uploads/downloads/2017/04/Impact_of_Emplo yee_Engagement_on_Performance.pdf

Hedge, J. W., \& Rineer, J. R. (2017). Improving Career Development Opportunities through Rigorous Career Pathways Research. Occasional Paper, RTI Press Publication. 
https://doi.org/10.3768/rtipress.2017.op.0037.1703

Homans, G. C. (1958). Social Behavior and Exchange. American Journal of Sociology, 63, 597-606. https://doi.org/10.1086/222355

Homans, G. C. (1961). Social Behavior: Its Elementary Forms. New York: Harcourt Brace Jovanovich.

Hughes, D., Bimrose, J., Barnes, S.-A., Bowes, L., \& Orton, M. (2005). A Systematic Literature Review of Research into Career Development Interventions for Workforce Development. Derby, UK: Centre for Guidance Studies.

Ivancevich, J. M., \& McMahon, J. T. (1982). The Effects of Goal Setting, External Feedback, and Self-Generated Feedback on Outcome Variables: A Field Experiment. Academy of Management Journal, 25, 359-372. https://doi.org/10.5465/255997

Jose, G., \& Mampilly, S. R. (2012). Satisfaction with HR Practices and Employee Engagement: A Social Exchange Perspective. Journal of Economics and Behavioural Studies, 4, 423-430. https://www.researchgate.net/publication/235790288 https://doi.org/10.22610/jebs.v4i7.343

Kahn, W. A. (1990). Psychological Conditions of Personal Engagement and Disengagement at Work. Academy of Management Journal, 33, 692-724. https://doi.org/10.5465/256287

Kazimoto, P. (2016) Employee Engagement and Organizational Performance of Retails Enterprises. American Journal of Industrial and Business Management, 6, 516-525. https://doi.org/10.4236/ajibm.2016.64047

Khamis, H. J., \& Kepler, M. (2010). Sample Size in Multiple Regression: $20+5 k$. Journal of Applied Statistical Science, 17, 505-517.

Lartey, F. M. (2020). Predicting the Number of Remote PHY Devices in a Hybrid Fiber/Coax Node+0 Deployment. Journal of Network Operations, 6, 19-36.

Latham, G. P., \& Locke, E. A. (1979). Goal Setting-A Motivational Technique That Works. Organizational Dynamics, 8, 68-80. https://doi.org/10.1016/0090-2616(79)90032-9

Long, R. J., \& Shields, J. L. (2010). From Pay to Praise? Non-Cash Employee Recognition in Canadian and Australian Firms. The International Journal of Human Resource Management, 21, 1145-1172. https://doi.org/10.1080/09585192.2010.483840

Macey, W. H., Schneider, B., Barbera, K. M., \& Young, S. A. (2009). Employee Engagement: Tools for Analysis, Practice, and Competitive Advantage. Hoboken, NJ: John Wiley \& Sons. https://doi.org/10.1002/9781444306538

Mankins, M., \& Garton, E. (2017). How Spotify Balances Employee Autonomy and Accountability. Harvard Business Review.

http://www.redpointconsulting.co.za/wp-content/uploads/2018/11/How-Spotify-Balan ces-Employee-Autonomy-and-Accountability.pdf

Mann, A., \& Dvorak, N. (2016). Employee Recognition: Low Cost, High Impact. https://www.gallup.com/workplace/236441/employee-recognition-low-cost-high-impa ct.aspx

Marks, G. (2017). Study: 71 Percent of Employees Are Looking for New Jobs. The Washington Post.

https://www.washingtonpost.com/news/on-small-business/wp/2017/10/19/study-71-pe rcent-of-employees-are-looking-for-new-jobs/

Merino, D. M., \& Privado, J. (2015). Does Employee Recognition Affect Positive Psychological Functioning and Well-Being? The Spanish Journal of Psychology, 18, E64. https://doi.org/10.1017/sjp.2015.67

Miller, J. (1982). Towards a Personal Guidance Base. London: Further Education Unit. 
Mone, E. M., \& London, M. (2018). Employee Engagement through Effective Performance Management: A Practical Guide for Managers (2nd ed.). New York: Routledge. https://doi.org/10.4324/9781315626529

Montani, F., Boudrias, J.-S., \& Pigeon, M. (2020). Employee Recognition, Meaningfulness and Behavioural Involvement: Test of a Moderated Mediation Model. The International Journal of Human Resource Management, 31, 356-384.

https://doi.org/10.1080/09585192.2017.1288153

Raza, S., Ansari, N. U. A., Humayon, A. A., Hussain, M. S., \& Aziz, K. (2017). Factors Affecting Millenials Employee Engagement in Government Sector. International Journal of Management Excellence, 10, 1195-1200. https://doi.org/10.17722/ijme.v10i1.947

Reed, V. A., Schifferdecker, K. E., \& Turco, M. G. (2012). Motivating Learning and Assessing Outcomes in Continuing Medical Education Using a Personal Learning Plan. Journal of Continuing Education in the Health Professions, 32, 287-294.

https://doi.org/10.1002/chp.21158

Rich, B. L., LePine, J. A., \& Crawford, E. R. (2017). Job Engagement: Antecedents and Effects on Job Performance. Academy of Management Journal, 53, 617-635. https://doi.org/10.5465/amj.2010.51468988

Saks, A. M. (2006). Antecedents and Consequences of Employee Engagement. Journal of Managerial Psychology, 21, 600-619. https://doi.org/10.1108/02683940610690169

Salanova, M., Agut, S., \& Peiró, J. M. (2005). Linking Organizational Resources and Work Engagement to Employee Performance and Customer Loyalty: The Mediation of Service Climate. Journal of Applied Psychology, 90, 1217-1227.

https://doi.org/10.1037/0021-9010.90.6.1217

Sarti, D. (2014). Job Resources as Antecedents of Engagement at Work: Evidence from a Long-Term Care Setting. Human Resource Development Quarterly, 25, 213-237. https://doi.org/10.1002/hrdq.21189

Schaufeli, W. B., Bakker, A. B., \& Salanova, M. (2006). The Measurement of Work Engagement with a Short Questionnaire: A Cross-National Study. Educational and Psychological Measurement, 66, 701-716. https://doi.org/10.1177/0013164405282471

Shafritz, J. M., \& Hyde, A. C. (2012). Classics of Public Administration. Boston, MA: Wadsworth Publishing.

Shantz, A., Alfes, K., Truss, C., \& Soane, E. (2013). The Role of Employee Engagement in the Relationship between Job Design and Task Performance, Citizenship and Deviant Behaviours. The International Journal of Human Resource Management, 24, 2608-2627. https://doi.org/10.1080/09585192.2012.744334

Shuck, B., Twyford, D., Reio, T. G., \& Shuck, A. (2014). Human Resource Development Practices and Employee Engagement: Examining the Connection with Employee Turnover Intentions. Human Resource Development Quarterly, 25, 239-270. https://doi.org/10.1002/hrdq.21190

Stansfield, T. C., \& Longenecker, C. O. (2006). The Effects of Goal Setting and Feedback on Manufacturing Productivity: A Field Experiment. International Journal of Productivity and Performance Management, 55, 346-358. https://doi.org/10.1108/17410400610653273

Tabachnick, B. G., \& Fidell, L. S. (2013). Using Multivariate Statistics (6th ed.). Upper Saddle River, NJ: Pearson.

Taber, K. T. (2018). The Use of Cronbach's Alpha When Developing and Reporting Research Instruments in Science Education. Research in Science Education, 48, 1273-1296. https://doi.org/10.1007/s11165-016-9602-2

Tate, D. T., Lartey, M. F., \& Randall, P. M. (2019). Relationship between Comput- 
er-Mediated Communication and Employee Engagement among Telecommuting Knowledge Workers. Journal of Human Resource and Sustainability Studies, 7, 328-347. https://doi.org/10.4236/jhrss.2019.72021

Taylor, F. W. (1911). The Principles of Scientific Management. New York: Harper Bros.

Thompson, C. A. \& Prottas, D. J. (2005). Relationships among Organizational Family Support, Job Autonomy, Perceived Control, and Employee Well-Being. Journal of Occupational Health Psychology, 10, 100-118. https://doi.org/10.1037/1076-8998.10.4.100

Turner, P. (2020). Measuring Employee Engagement. In Employee Engagement in Contemporary Organizations (pp. 193-222). Cham: Palgrave Macmillan. https://doi.org/10.1007/978-3-030-36387-1

White Jr., R. D. (2010). The Micromanagement Disease: Symptoms, Diagnosis, and Cure. Public Personnel Management, 39, 71-76. https://doi.org/10.1177/009102601003900105

Wynarczyk, P., Watson, R., Storey, D. J., Short, H., \& Keasey, K. (2016). Managerial Labour Markets in Small and Medium-Sized Enterprises. New York: Routledge. https://doi.org/10.4324/9781315544243 